\title{
REENQUADRANDO O CONFLITO NA TRADUÇÃO ${ }^{1}$
}

\author{
Mona Baker 1 \\ ${ }^{1}$ University of Manchester, Manchester, United Kingdom \\ Tradução de: Cristiane Roscoe-Bessa² \\ Flávia Lamberti \\ ${ }_{2}^{2}$ Universidade de Brasília, Brasília, Distrito Federal, Brasil.
}

\begin{abstract}
Resumo: Tendo em vista a teoria narrativa e o conceito de enquadre segundo a concepção desenvolvida pela literatura referente a movimentos sociais, este artigo explora diversos caminhos pelos quais tradutores e intérpretes destacam, enfraquecem e modificam aspectos polêmicos da(s) narrativa(s) produzida(s) no texto ou enunciado original. Inicialmente se apresentam um panorama dos axiomas e vantagens da abordagem narrativa em comparação com teorias da tradução e o conceito de enquadre no contexto do discurso ativista. Em seguida são considerados pontos ou locais de um texto propriamente dito ou de outros materiais relacionados em que o (re)enquadre pode ser realizado; são dados vários exemplos de estratégias de enquadre usadas na tradução escrita e em vídeo. Os exemplos são procedentes de traduções do par inglês e árabe no contexto dos conflitos do Oriente Médio e da chamada Guerra ao Terror. Ressalte-se que as abordagens teóricas descritas não são específicas de uma língua ou contexto específicos.
\end{abstract}

Palavras-chave: Narrativa; Enquadre; Guerra ao terror; Árabe; Conflito do Oriente Médio

\footnotetext{
${ }^{1}$ Artigo publicado na revista Social Semiotics em 2007. A presente tradução foi autorizada para ser publicada em português pela Editora Taylor \& Francis (Taylor $\&$ Francis Ltd, <http://www.tandfonline.com >) e pela autora Mona Baker, aos quais agradecemos imensamente. Referência bibliográfica completa do artigo original: BAKER, Mona. Reframing Conflict in Translation. Social Semiotics, v. 17, n. 2, p. 151-169, 2007.
} 


\title{
RE-ENFRAMING THE CONFLICT IN TRANSLATION
}

\begin{abstract}
This article sets off from both the concepts of narrative theory and enframing - the latter developed within the realm of literature regarding social movements. In so doing, the purpose is to explore the many manners whereby translators and interpreters might emphasise, mitigate, and modify what one could consider divisive features present in the narrative(s) produced within the original text and/or utterance. At first, we provide an overview unfolding the axioms and advantages of applying, within the context of activist discourses, a narrative approach in opposition to translation theories - as well as the notion of enframing. Followingly, our investigation is directed towards the specific spots and places of a text per se, or of any other related resources, wherein (re)framing could be effected; diverse examples of framing strategies deployed in both written and video translation are thus exposed. Such examples surface from translations of the English and Arabic pair, within the context of Middle East conflicts and the so-called War on Terror. It should be stressed nonetheless that the theoretical approaches herein described do not belong specifically to a certain language or context.
\end{abstract}

Keywords: Narrative; Enframing; War on Terror; Arabic; Middle East conflict.

Este artigo recorre a conceitos da teoria narrativa, da sociologia e dos estudos dos movimentos sociais com o intuito de examinar algumas das maneiras pelas quais tradutores e intérpretes reenquadram aspectos de conflitos políticos e, assim, terminam participando da construção da realidade social e política. O modelo de análise adotado aqui foi elaborado em maiores detalhes em Baker (2006a) e também (BAKER, 2005, 2006b). Esse modelo parte do conceito de narrativa como entendida em algumas vertentes da teoria social e da comunicação, e não na narratologia ou linguística. Aqui, o termo "narrativa" é utilizado de forma sinônima com "história": narrativas são histórias que contamos a nós mesmos e aos outros sobre o(s) mundo(s) em que vivemos. É a nossa crença nessas histórias que guia nossas ações no mundo real. Neste sentido, a narrativa não é um gênero tampouco uma modalidade opcional de comunicação: a narração, de acordo com Walter Fischer, "não é 
uma modalidade do discurso apresentada por alguém como uma escolha deliberada mas a forma do conhecimento como nós o apreendemos pela primeira vez" (1987, p. 193).

Minha escolha da narratividade como uma estrutura teórica é motivada por meu descontentamento com as abordagens teóricas existentes às quais geralmente recorremos para tentar explicar o comportamento dos tradutores e dos intérpretes. Uma considerável parte da literatura sobre tradução especificamente tem fundamentos no conceito de normas, como elaborado na teoria dos polissistemas e na proposta de Gideon Toury. A teoria das normas incentiva analistas a se concentrarem em comportamento repetitivo, abstrato e sistemático, o que termina por privilegiar padrões de socialização nesse comportamento e por desprezar as várias tentativas individuais e coletivas de enfraquecer padrões e dogmas políticos e sociais dominantes. De forma similar, a teoria das normas não tem nada a dizer sobre os intricados padrões de interação entre modelos de comportamentos repetidos e estáveis e as tentativas contínuas de subverter esse comportamento - a interação entre dominação e resistência, que é um aspecto tradutório que destaco em meu próprio trabalho. Pode-se argumentar que a teoria das normas não considera as circunstâncias políticas e sociais que levam a tais padrões de dominação e resistência.

A teoria narrativa nos permite ir além da dicotomia de ampla repercussão de Lawrence Venuti, referente às estratégias de estrangeirização e de domesticação (VENUTI, 1993, 1995), reformuladas como estratégias minoritárias e majoritárias (VENUTI, 1998). Além de reduzir a rica variedade de posicionamentos que tradutores podem adotar com relação aos textos, autores e sociedades, essas dicotomias também mascaram os diferentes posicionamentos que um tradutor pode ter em um mesmo texto - elas reduzem também as maneiras pelas quais um tradutor pode lidar com os vários aspectos de um texto, fazendo-o optar por uma estratégia mais estrangeirizante ou domesticadora. Um exame rápido de alguns dos textos com os quais venho trabalhando em minha pesquisa sugere que tradutores oscilam dentro de um mesmo texto entre escolhas 
que Venuti poderia considerar domesticadoras ou estrangeirizantes. É importante ressaltar que essa oscilação serve a uma finalidade no mundo real - não é aleatória tampouco irracional.

Para encontrar um equilíbrio entre a ênfase da teoria das normas no comportamento repetitivo e abstrato e o efeito simplificativo das dicotomias de Venuti, necessitamos de um quadro que reconheça os posicionamentos variados e permanentemente negociáveis que um tradutor pode ter em relação aos textos, autores, sociedades e ideologias dominantes. Daqui decorre meu interesse na teoria narrativa e minha tentativa de aplicá-la a uma variedade de traduções escritas e de atividades de interpretação. Não acredito que a teoria narrativa por si só tenha elementos para resolver todas as lacunas da teorização atual na tradução nem que essa teorização (inclusive a teoria das normas e a dicotomia de Venuti) seja inócua ao lidar com a variedade de problemas relevantes ao comportamento dos tradutores e dos intérpretes. Apresento os pontos positivos da teoria narrativa como se segue.

Primeiramente, a teoria narrativa não privilegia categorias essencialistas e reducionistas tais como raça, gênero, etnias e religião; ao contrário, essa reconhece a natureza permanentemente negociável de nosso posicionamento com relação à realidade social e política. Como Hall et al. defendem, a narratividade "oferece uma maneira de conceber a identidade que não é universal nem essencialista, mas sim específica de uma cultura e de um tempo" (2003, p.38). Essa nos permite, assim, ir além da ênfase em diferenças culturais supostamente inerentes e no tipo de política de identidade que plasmou muito do trabalho de tradução e interpretação até hoje, principalmente trabalhos sobre traços culturais e padrões de comportamento (por exemplo, KATAN, 2004), sobre gênero (GODDARD, 1990; SIMON, 1996; VON FLOTOW, 1997) e sobre sexualidade (HARVEY, 1998, 2003a; KEENAGHAN, 1998). Sem desmerecer a importância e o valor desse tipo de trabalho, defendo que é hora de dar um passo adiante. A política de identidades e as estruturas que tematizam as diferenças em geral constituem o último modelo de que necessitamos neste momento específico da 
história, quando teorias perniciosas como a da obra Clash of civilizations de Samuel Huntington $(1993$, 1996) estão tentando destacar ou mesmo inventar um panorama completo de diferenças - não para fortalecer grupos oprimidos de acordo com a tradição da política de identidades, mas para justificar a mais criminosa e perigosa política internacional. Essas teorias da diferença politicamente motivadas permitem que Huntington, por exemplo, advogue que há algo como uma "propensão muçulmana para o conflito violento" (1996, p. 258) e que "a sobrevivência do mundo ocidental depende de os americanos reafirmarem sua identidade ocidental e de ocidentais aceitarem sua civilização não universal singular, e unirem-se para renová-la e preservá-la das provocações das sociedades não ocidentais" (1996, p. 20-21).

Teorias perniciosas e políticas internacionais irresponsáveis à parte, é também justo ressaltar que, apesar de atraente e potencialmente libertadora em determinados contextos políticos, a política de identidades sempre teve limitações consideráveis. $\mathrm{O}$ mais grave é que ela agrupa pessoas que compartilham determinados traços externos (mulheres, negros, homossexuais, paquistaneses) e termina negligenciando a variação individual dentro de um mesmo grupo. Ao dar ênfase a uma característica ou qualidade em detrimento de outras, ela também destaca em demasia a identidade de indivíduos. Ao contrário, o que devemos fazer é localizar a variedade de narrativas na qual se inserem tradutores e intérpretes dentro do conjunto de narrativas que caracterizam seu comportamento no mundo real - incluindo o seu discurso como tradutores e/ou intérpretes, o que não significa ignorar o fato óbvio de que nossa posição em uma comunidade cultural, racial ou religiosa em particular e em um determinado ponto no tempo influencia nosso comportamento de maneiras específicas. Mas a teoria narrativa reconhece que essa influência não é inevitável nem previsível. Atualmente, por exemplo, ser judeu pode significar: (a) apoio irrestrito a Israel e ao zionismo; (b) qualquer variação no apoio irrestrito às políticas atuais de Israel; (c) recusa a se identificar como um judeu e completa falta de interesse no conflito do Oriente Médio; (d) ou, como 
está ocorrendo cada vez mais em grande parte das comunidades judaicas, um compromisso de se envolver em atividades que expõem e depreciam o empreendimento zionista. Mesmo que alguém se identifique como judeu, esse fato não diz muito sobre como essa pessoa age no mundo real nem explica seu comportamento, a menos que saibamos algo sobre as narrativas a que se subscreve ou que possamos deduzi-las pelo seu discurso e suas ações.

Em segundo lugar, seguindo o raciocínio anterior, a teoria narrativa permite ver atores sociais, incluindo tradutores e intérpretes, como indivíduos da vida real em vez de abstrações teóricas. Whitebrook defende que a teoria em geral "frequentemente falha em tornar o agente político em algo concreto" e que o "caráter é tratado como uma questão de variáveis que um observador deve avaliar quando se tenta compreender ou prever o comportamento de alguém" (2001, p. 15). Sua crítica assim como sua proposta de adotar a teoria narrativa como uma maneira de se livrar dessa abstração aplicam-se certamente à teorização sobre a tradução e a interpretação:

\begin{abstract}
Voltar-se às narrativas permite teóricos sem posicionamento claro, portadores de uma identidade típica e representativa, a serem compreendidos como indivíduos - personagens com uma série de características singulares, incluídos mas não confinados a seu contexto político e/ou a sua identidade de grupo. (WHITEBROOK, 2001, p.15, tradução nossa).
\end{abstract}

Em terceiro lugar, a teoria narrativa permite explicar o comportamento de forma dinâmica, e não em termos estáticos - ela reconhece a complexidade de estar inserido em narrativas que se interceptam ou mesmo que concorrem. A narratividade assim "insere o ator em relacionamentos e histórias que mudam no decorrer do tempo e do espaço e impossibilita a estabilidade de categorias em ação" (SOMERS; GIBSON, 1994, p.65, tradução nossa). Não há espaço aqui para comportamentos ou escolhas estanques em 
macrocategorias tais como estrangeirizante versus domesticadora, aculturação versus exotização, tampouco fiel versus livre - nem mesmo dentro de um único texto. Igualmente, visto que o ator está sempre "inserido" em relacionamentos e histórias, não há porque supor uma posição privilegiada de "objetividade" ou " "neutralidade" em relação às narrativas que traduzimos, interpretamos ou analisamos. A teoria narrativa incentiva-nos a refletir e questionar as narrativas com as quais temos contato e que moldam nosso comportamento, mas não há suposição aqui de que podemos suprimir nossa subjetividade ou estar fora daquelas narrativas, até mesmo quando raciocinamos sobre elas.

Em quarto lugar e o mais importante na minha opinião: a teoria narrativa reconhece o poder das estruturas sociais e o funcionamento do "sistema", mas não impossibilita a resistência ativa do indivíduo ou do grupo. Ela se ocupa também de questões de dominação e de resistência, da natureza ritual da interação (no sentido de Erving Goffman) assim como dos instrumentos de questionamento e menosprezo dos rituais. E finalmente, embora trabalhos sobre a narratividade nos estudos sociais e da comunicação praticamente não se ocupem de questões linguísticas ou da tradução, a teoria narrativa é passível de ser aplicada a ambas, de forma que permite explicar escolhas tradutórias com relação a contextos sociais e políticos, mas sem perder de vista o evento e o texto específico. Este é um aspecto da teoria narrativa que venho tentando elaborar em detalhe em meu trabalho e que pretendo demonstrar com um exemplo ao final deste artigo.

\section{Enquadre e reenquadre}

As narrativas, como expliquei acima, são as histórias às quais nos subscrevemos - aquelas em que acreditamos ou contemplamos como potencialmente válidas - e que determinam nosso comportamento e atitude para com os outros e os eventos nos quais estamos inseridos. Com o sentido aqui empregado, as narrativas não são 
cronologias, não são um repertório de acontecimentos: são as histórias constituídas no tempo e por alguma razão, de forma que nos permitam tomar decisões no mundo real.

Somers $(1992,1994,1997)$ e Somers e Gibson (1994) sugerem que as narrativas são constituídas por quatro características interdependentes. Temporalidade significa que as narrativas estão inseridas em um tempo e espaço e muito de seu significado provém do momento e do local da narrativa. Relacionalidade significa que a mente humana não consegue extrair sentido de eventos isolados ou de uma colcha de eventos que não compõem uma narrativa. Para sua interpretação, cada elemento de uma narrativa depende de sua localização dentro da rede dos elementos que compõem a narrativa; não há como interpretá-los isoladamente. Apropriação seletiva é a terceira característica central da narratividade. Visto que é impossível tecer uma história coerente incluindo cada detalhe da experiência, as narrativas são necessariamente construídas de acordo com os critérios avaliativos que permitem e direcionam uma apropriação seletiva de um conjunto de eventos ou elementos a partir da grande quantidade de eventos incontáveis e sobrepostos que constituem a experiência. A última e mais importante característica é a narratividade causal, que proporciona significado a acontecimentos independentes e se sobrepõe a sua ordem cronológica ou categoria (SOMERS, 1997, p. 82). Ela nos permite transformar uma série de proposições em uma sequência inteligível sobre a qual podemos formar uma opinião, o que proporciona aos eventos descritos um significado moral e ético (BAKER, 2006a, p. 65). É a nossa subscrição a um padrão específico de narratividade causal na narrativa do Oriente Médio, por exemplo, que nos leva a interpretar mais um incidente de ataque suicida em Israel ou como uma ameaça à segurança de Israel, o que fornece evidência da necessidade de medidas tais como o Muro e os assassinatos com alvo específico (ataques homicidas), ou como uma consequência inevitável exatamente dessas medidas, o que, por sua vez, fornece evidência de que a solução se encontra em adotar outras alternativas. Essas alternativas, por sua vez, variarão de acordo com pa- 
drões mais específicos de narratividade causal que distinguem uma narrativa individual de outras, mesmo dentro de um mesmo grupo maior, como, por exemplo, ativistas políticos. Nem todos os ativistas do Movimento Solidário à Palestina, por exemplo, concordam necessariamente que a solução ao conflito esteja simplesmente em encerrar a ocupação, de 1967, ao longo da fronteira. Alguns insistem que a solução está na reconfiguração da Palestina/Israel como um único estado secular para todos os seus cidadãos, denominada hoje a "Solução do Estado Único". Os argumentos a favor ou contra qualquer solução só serão coerentes dentro de padrões específicos de narratividade causal que distinguem uma narrativa da outra.

Para que todas as características descritas da narratividade tornem-se plausíveis e para que uma série de eventos seja constituída como uma narrativa com um padrão específico de narratividade causal, aqueles que fazem a narrativa devem lançar mão de uma quantidade considerável de trabalho discursivo. O conceito de enquadre, principalmente o conceito mais ativo de enquadre, pode ser útil para o esboço de algumas das maneiras em que esse trabalho discursivo é realizado. Esses conceitos recebem diversas definições na literatura, mas, de forma geral, podem ser interpretados tanto de forma passiva, como "entendimentos" que emergem da interação, como de forma ativa, como movimentos discursivos deliberados e projetados para antecipar e direcionar as interpretações e atitudes de outros com relação a uma série de eventos. O primeiro, uma definição geralmente passiva de enquadre, é característica do trabalho de Erving Goffman, que argumenta: "o enquadre feito por um indivíduo irá estabelecer o significado para ele" (1974, p. 345; grifou-se). Definições similares podem ser encontradas em trabalho de outros acadêmicos que seguem a linha de Goffman. Tannen e Wallat (1993, p. 60), por exemplo, definem enquadres como "uma percepção de qual atividade está em jogo, como os interlocutores atribuem significado ao que dizem". A literatura sobre movimentos sociais, em contraste, tende a tratar enquadre como um processo ativo de significação. Para os ativistas e aqueles interessados em estudar seu comportamento, o processo de enquadrar 
eventos para outros é uma parte essencial do fenômeno do ativismo, o que envolve crucialmente estabelecer estruturas de antecipação que direcionam a interpretação de outros com relação a eventos, geralmente como um desafio direto às interpretações dominantes dos mesmos eventos em uma certa sociedade. Esse trabalho discursivo de enquadrar eventos e assuntos em relação a um grupo específico de destinatários é importante não somente porque enfraquece narrativas dominantes de um dado assunto (ameaça nuclear, Palestina, a chamada Guerra ao Terror), mas também porque é uma estratégia chave para formar redes e comunidades de ativistas. Isso permite que movimentos sociais cresçam e atraiam adeptos:

Enquanto, no dia a dia, todos os atores sociais lançam mão de enquadres a fim de produzir e de manter significados locais, analistas do enquadre já reconhecem que o processo estratégico de construção e de gerência do enquadre é central à missão das organizações de movimentos sociais que tentam substituir "um sistema de opinião dominante que sustente ação coletiva para a mudança" (GAMSON et. al., 1982, p. 15). Nesse sentido, processos de enquadre fornecem um mecanismo por meio do qual indivíduos podem se identificar ideologicamente com os objetivos do movimento e se tornar participantes potenciais em ações desse movimento. (CUNNINGHAM; BROWNING,2004, p.348, tradução nossa).

O conceito de enquadre tem estreita ligação com a pergunta de como a teoria narrativa permite que consideremos a narrativa imediata elaborada no texto que está sendo traduzido ou interpretado e as narrativas maiores em que o texto é inserido e como isso, por sua vez, nos permite ver escolhas tradutórias não apenas como desafios linguísticos locais mas também como contribuições diretas às narrativas que dão forma a nosso mundo social. Aqui, consideramos cada escolha - pelo menos potencialmente - como um tipo de índice que ativa uma narrativa, uma história de como é o mundo ou algum de seus aspectos. Algumas escolhas, princi- 
palmente aquelas relacionadas a como denominamos um evento, um lugar ou um grupo, assim como a maneira que posicionamos indivíduos e comunidades no espaço social e político com o uso de pronomes e advérbios de lugar, entre outros, permitem que moldemos a narrativa para outros, no movimento social, no sentido ativista de enquadre. ${ }^{2}$

Tradutores e intérpretes que trabalham com chinês e inglês, por exemplo, estão cientes de que os acontecimentos de 1997 em Hong Kong podem ser denominados tanto A Transferência de Soberania, a referência padrão em inglês, ou (literalmente) como $O$ Retorno à Terra Mãe, a referência padrão em chinês. ${ }^{3}$

Além disso, eles estão geralmente cientes de que essas escolhas não existem em variação livre, mas têm sérias implicações no mundo real. De forma semelhante, ao traduzir um texto sobre os acontecimentos de 1956 no Oriente Médio, deve-se escolher entre duas designações concorrentes, das quais nenhuma representa um desafio linguístico. ${ }^{4}$ A primeira escolha, predominante no discurso ocidental e inserida em uma narrativa bem aceita no Ocidente, é denominar tais acontecimentos de $A$ Crise do Canal de Suez. A escolha de $A$ Crise do Canal de Suez ativa imediatamente a narrativa das potências invasoras; para Grã-Bretanha, França e Israel, era útil e expediente narrar esses eventos como uma crise política. A designação usada no mundo Árabe, praticamente inexistente no Ocidente, é a Agressão Tripartite. A escolha padrão em árabe ativa uma estru-

${ }^{2}$ Enquadre, neste sentido, não se restringe a ativismo, embora isso também dependa da definição de ativismo. Alguns dos exemplos discutidos mais adiante provêm de fontes muito nocivas para serem consideradas 'ativistas'. Essas incluem grupos de defesa como o Middle East Media Research Institute (MEMRI) que se ocupam de demonizar as comunidades árabes e islâmicas e de colocar o Ocidente em oposição ao resto.

${ }^{3}$ Escolhas semelhantes no contexto chinês incluem $\mathrm{O}$ massacre de Tiananmen versus $\mathrm{O}$ incidente de Tiananmen ou O Protesto de Tiananmen. Esses exemplos são de Kevin Lin, intérprete chefe do Ministério das Relações Exteriores da Grã-Bretanha. ${ }^{4}$ Em 1956, o Egito foi atacado pela Grã-Bretanha, França e Israel após a decisão do Egito de nacionalizar o Canal de Suez, que faz a conexão do Mar Mediterrâneo com o Mar Vermelho e o Golfo de Suez. 
tura narrativa completamente diferente, inserida na consciência e nas alianças daqueles que sofrem esse ataque. Os tradutores não substituem necessariamente $A$ Crise do Canal de Suez por Agressão Tripartite ao traduzir um texto em inglês para o árabe. Provavelmente reproduzirão essa designação com uma tradução próxima, talvez porque se subscrevam a uma narrativa da tradução como prática neutra e "profissional". Porém, mesmo nesse caso, sua escolha por promover e legitimar uma ou outra narrativa terá implicações. E há outras escolhas: tradutores podem deixar a designação como está, mas comentá-la ou mesmo questioná-la na introdução ou em notas de rodapé. Enquanto a escolha de $A$ Transferência de Soberania ou $A$ Crise do Canal de Suez pode enquadrar a narrativa de uma maneira específica, exatamente este enquadre pode, por sua vez, ser questionado, e a narrativa inteira reenquadrada, em uma variedade de pontos ou locais de um texto propriamente dito ou de outros materiais relacionados.

A questão, então, é não tratar as escolhas tradutórias como aleatórias, sem implicação no mundo real. Tampouco a teoria narrativa nos incentiva a tratar uma escolha específica (tal como $A$ Crise do Canal de Suez) como a realização de uma norma ampla e abstrata ligada a outras escolhas abstratas, tais como optar por reproduzir as estruturas sintáticas do texto fonte porque há uma norma predominante de adequação em vez de aceitabilidade ${ }^{5}$ na cultura alvo em um momento específico no tempo. A estrutura da teoria narrativa incentiva-nos a evitar essas abstrações amplas e pensar em escolhas individuais inseridas e engajadas na elaboração de uma realidade política concreta.

\footnotetext{
${ }^{5}$ Na concepção de Toury $(1980,1995)$, a norma inicial que governa qualquer tradução envolve a escolha entre adequação e aceitabilidade. Uma tradução subscreverá às normas do texto, língua e cultura no original (sendo, portanto, adequada) ou às normas da língua e cultura alvos (sendo portanto aceitável). Aderência às normas do original determina a adequação da tradução em relação ao texto original; aderência às normas da cultura alvo determina a aceitabilidade nessa cultura.
} 


\section{Locais e estratégias de enquadre}

Processos de (re)enquadre podem recorrer a praticamente qualquer recurso linguístico ou não-linguístico a fim de estabelecer um contexto interpretativo ao leitor ou ouvinte. Isso pode incluir a exploração de recursos paralinguísticos como a entonação e a tipografia, recursos visuais como cor, imagem e layout, e também recursos linguísticos como mudança de tempo verbal, dêixis, mudança de código e uso de eufemismos. Usuários da língua, tradutores e intérpretes em especial, podem também explorar os aspectos da narratividade (temporalidade, relacionalidade, apropriação seletiva e narratividade causal) para enquadrar e reenquadrar um texto ou enunciado para um conjunto de destinatários. Tradutores de textos escritos podem fazer isso no corpo da tradução ou, de outro modo, em materiais relacionados com a tradução. Essa distinção pode ser muito importante em alguns contextos por causa do papel essencial que os conceitos de precisão e de fidelidade tendem a ter no contexto da tradução profissional, em especial da tradução sensível no âmbito político.

Nesse sentido, organizações neoconservadoras, tais como o MEMRI ${ }^{6}$ especializadas na circulação de traduções de textos originais em árabe cuidadosamente selecionados com o intuito de preparar uma narrativa das sociedades árabes como extremistas, antisemitas e uma ameaça às democracias ocidentais, têm tomado cuidado em relação à precisão de suas traduções, uma vez que a sua credibilidade pode facilmente ser comprometida se seus oponentes identificarem e divulgarem uma lista de erros nessas traduções, sejam erros apresentados de forma deliberada ou não. A maior parte do enquadre realizada pelo MEMRI e por seu afiliado próximo, a Watching America, ${ }^{7}$ tem consequência externa ao/à texto/tradução propriamente. De início, o aspecto narrativo

\footnotetext{
${ }^{6}$ Ver www.memri.org. Para uma discussão mais detalhada sobre o MEMRI e suas atividades de tradução, ver Baker (2006a:, p.3-76, p.108-109).

${ }^{7}$ Ver www.watchingamerica.org.
} 
de apropriação seletiva permite ao MEMRI e à Watching America enquadrar o mundo árabe como extremista e perigoso a partir da simples escolha de traduzir os piores exemplos de discurso árabe, os quais circulam livremente na mídia e no congresso americano. De forma curiosa, o MEMRI tem uma categoria especial de escritores denominados reformistas: vozes esparsas do mundo árabe e do Irã traduzidas e citadas no site diversas vezes; esses reformistas defendem liberdade de expressão, direitos das mulheres e assim por diante. A seleção 'cosmética' ocasional de uma fonte não extremista serve para dar uma aparência de equilíbrio à cobertura do MEMRI, ao mesmo tempo em que reforça o retrato geral do mundo árabe e do Irã como berço do extremismo que suprime as mesmas vozes na região - vozes que estão recebendo espaço, de forma magnânima, no site americano.

Em segundo lugar, ao manter a tradução muito perto do original, o MEMRI e a Watching America podem mudar o título de um texto para o enquadre da narrativa como extremista, ameaçadora ou simplesmente estrangeira em termos discursivos. Por exemplo, uma recente tradução em inglês de um artigo de um jornal palestino Alhayat Aljadeeda foi divulgada no website da Watching America com o título 'Oh América... Oh, Império das Contradições. ${ }^{8}$ Retrotraduzido de forma bem próxima, o título original em árabe é muito menos rebuscado e exótico: diz 'Sinais no caminho: América e Democracia!!!'. ${ }^{9}$

Em terceiro lugar, a WatchingAmerica insere imagens, com legendas convenientes, no texto em inglês que enquadram a narrativa traduzida como parte da metanarrativa maior da Guerra ao Terror. As Figuras 1 e 2, por exemplo, juntamente com as legendas específicas, aparecem na tradução do artigo do Alhayat Aljadeeda.

\footnotetext{
${ }^{8}$ http://www.watchingamerica.com/alhayataljadeeda000003.shtml.

${ }^{9}$ http://wwwalhayat-j.com/details.php?opt $=1 \& \mathrm{id}=22102 \& \mathrm{cid}=394$.

${ }^{10}$ Imagens e legendas das Figuras 1 a 4 estão na tradução em inglês da Watching America do artigo de Alhayat Aljadeeda, disponível em < http://watchingamerica.com/alhayataljadeeda000003shtml $>$ e acessado em 25 de outubro de 2006. A autora tentou identificar os proprietários dos direitos autorais e responderá a possíveis questionamentos.
} 


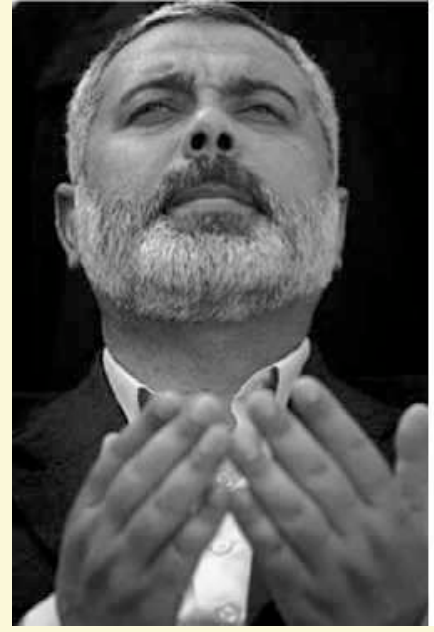

Figura 1 - O Primeiro-Ministro palestino Ismail Haniyeh reza antes de fazer um discurso, provavelmente para arrecadar fundos... provenientes possivelmente do Irã. ${ }^{10}$

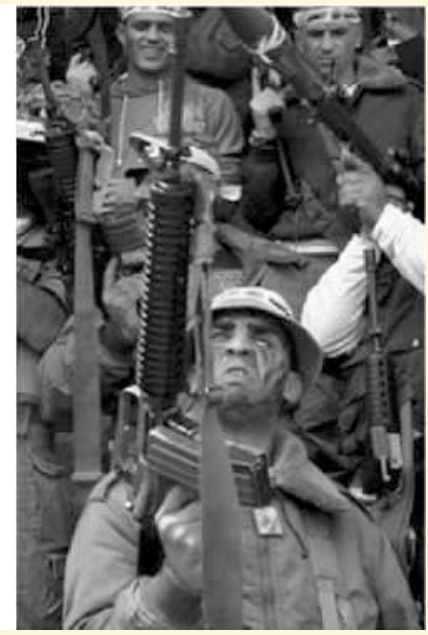

Figura 2 - Um soldado da Brigada do Mártir Al-Aqsa na Cisjordânia, durante um evento para lembrar um dos vários atos de violência ocorridos lá.

Em quarto, e talvez o aspecto mais importante, cada tradução em inglês de um artigo de um jornal árabe é acompanhada de um link ao vídeo, fornecido pelo MEMRI, que age como um mecanismo de enquadre posterior, motivando o leitor a interpretar até mesmo a frase mais lógica de um discurso árabe como contendo um subtexto extremista. $\mathrm{O}$ artigo do Alhayat Aljadeeda é acompanhado de um link para o vídeo com legendas convenientes, como se verifica na Figura 3. É interessante observar que as traduções de outras línguas não recebem o mesmo tratamento: as traduções do chinês, espanhol, francês e holandês e de uma série de outras línguas são apresentadas no site sem links aos vídeos do MEMRI que demonizam a comunidade em questão. A única outra língua que recebe esse tratamento especial (ou está sujeita a essa estratégia de enquadre) é o persa, como se pode esperar. 


\section{Vídeo da palestina: comemoração do ataque suicida em uma sede de apoio ao Hamas}

Iqra TV, Palestina: Excertos do discurso para levantar fundos feito pelo clérigo iemenita Abd Al-Majid Al-Zindani, de 23 de março, 00:08:18, Via MEMRI

'Após esforços, políticas e planos sem sucesso, e as pessoas já em quase desespero, o mundo inteiro ficou surpreso pela decisão do Hamas. Qual foi a decisão? Uma intifada. Uma intifada? Onde? Na Palestina. Na Palestina!'

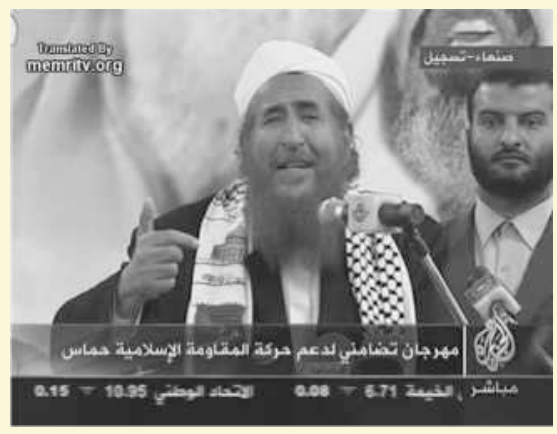

Figura 3 - O clérigo iemenita Abd Al-Majid Al-Zindani. Vídeo com notas que acompanham o artigo do Alhayat Aljadeeda, cortesia do MEMRI.

Além de imagens, de legendas e da manipulação dos títulos, os paratextos são importantes recursos de enquadre em traduções de livros: esses compreendem imagens na capa e contracapa, introduções, prefácios e notas de rodapé. $\mathrm{O}$ tradutor geralmente não produz a apresentação de imagens na capa e contracapa ${ }^{11}$ mas normalmente escreve os prefácios, as introduções e as notas de rodapé. Duas tra-

${ }^{11}$ Para análises interessantes das capas e das contracapas das traduções publicadas, ver Watts (2000), Harvey (2003b), Asimakoulas (2005).

Cad. Trad., Florianópolis, v. 38, no 3, p. 518-548, set-dez, 2018 
duções em árabe de $O$ choque de civilizações de Samuel Huntington foram divulgadas em um curto período de tempo, a primeira em 1998 no Egito (traduzida por Tal'at Al-Shayib) e a segunda em 1999 na Líbia (traduzida por Malik Obeid Abu Shuhayaa e Mahmoud Mohamed Khalaf). Ambas as traduções apresentam introduções longas. A tradução da Líbia apresenta duas, sendo que a primeira, de ambos os tradutores, tem quatro páginas, oferece um resumo do conteúdo do livro, conta a respeito da grande controvérsia e afirma o seguinte (HUNTINGTON, 1999, p. 11, tradução nossa):

Considerando a estrutura caótica e a incoerência do texto e as falhas na metodologia adotada pelo autor, e com o intuito de identificar o propósito subjacente da tese do choque de civilizações, foi necessária a desconstrução dos mecanismos e das concepções desse discurso. Malik Obeid Abu Shuhayaa [um dos tradutores] preparou assim um estudo das concepções políticas e intelectuais do discurso do choque de civilizações e dos mecanismos utilizados para delimitar sua abordagem conceitual, persuadir e conseguir apoio. Esse estudo é intitulado 'Uma contribuição inicial à conscientização do outro: as concepções e os mecanismos do Choque de Civilizações'.

Esse estudo propriamente, escrito por um dos tradutores, como indicado na citação acima, constitui a segunda introdução. Em texto de 49 páginas, o tradutor questiona Huntington e sua teoria diretamente. A tradução egípcia de 1998 tem introdução de 19 páginas preparada não pelo tradutor mas pelo intelectual árabe (Salah Qunswah), com vistas a enfraquecer a tese do livro e desafiar seus principais pilares (HUNTINGTON, 1998). Todas as três introduções (duas nas traduções líbias e uma na tradução egípcia) precedem as versões árabes do prefácio do próprio Huntington do seu livro e antecipam a reação do leitor aos argumentos apresentados no texto original. Essas introduções enquadram os textos traduzidos como negativos, motivando o leitor a interpretar a tese de 
Huntington a partir de um ângulo específico até mesmo antes de começar a lê-la.

Notas de rodapé são também preparadas pelos tradutores e podem ter função similar de enquadre. O livro Messages to the World: The Statements of Osama Bin Laden (LAWRENCE; HOWARTH, 2005), nesse sentido, apresenta traduções com muitas notas dos discursos de Bin Laden, fazendo uso amplo de notas de rodapé com o intuito de reenquadrar sua narrativa pessoal - e por meio disso as narrativas do fundamentalismo islâmico, o chamado choque de civilizações e a 'Guerra ao Terror' - como consequência direta das políticas externas ocidentais ao invés de produto de uma mentalidade que, no discurso da Guerra ao Terror, é normalmente retratada como nada mais além do que um mal difícil de ser explicado. Em uma resenha do livro na London Review of Books, Charles Glass observa que Bin Laden "não parece desequilibrado, como seus detratores insistem. Sua mensagem é clara: deixe o mundo islâmico em paz, e este o deixará em paz. Matem muçulmanos e eles o matarão" (GLASS, 2006, p.14). Como se chega a essas ideias?

O livro foi organizado por Bruce Lawrence, mas os discursos individuais e as declarações foram traduzidos por James Howarth. A introdução principal elaborada pelo editor (LAWRENCE; HOWARTH, 2005, p. xi-xxiii) e as Notas do Tradutor (LAWRENCE; HOWARTH, 2005, p. ix-x) esclarecem que o editor responsabiliza-se de forma explícita pelas introduções menores, apresentadas no início das traduções individuais, das declarações de Bin Laden, e o tradutor pelas notas de rodapé que acompanham cada tradução. Em conjunto, as introduções e as notas de rodapé enquadram Bin Laden como equilibrado e perspicaz, instruído e lúcido. Nesse sentido, a curta introdução do editor a uma carta de Bin Laden divulgada na Internet no dia 6 de outubro de 2002, e que aparece na coleção sob o título de 'To the Americans' (LAWRENCE; HOWARTH, 2005, p. 160-72), diz o seguinte: 
Esse retrato dos Estados Unidos baseia-se em um chamado ao povo americano para se converter ao Islã. Apesar de fantástica a possibilidade dessa conversão, como a carta mesmo indica ("eu duvido que aconteça"), o apelo tem uma função prática na comunidade muçulmana. O propósito é responder aos críticos muçulmanos do 11 de setembro que argumentaram que a al-Qaeda não ofereceu aos americanos uma oportunidade de se converter ao Islã antes do ataque e, portanto, violou uma regra de Deus: "Nunca punimos antes de enviarmos uma mensagem". Os detalhes exaustivos da carta é a prova de Bin Laden aos muçulmanos de que ele tentou explorar vários caminhos para resolver essa guerra por meios pacíficos, dando avisos acerca de uma destruição próxima dos americanos se esses se recusassem a ouvir o seu conselho. (LAWRENCE; HOWARTH, 2005, p. 160)

Uma nota de rodapé do tradutor a uma outra declaração feita por Bin Laden em uma entrevista a um jornal australiano, divulgada na mesma coleção ('The Saudi Regime'; LAWRENCE; HOWARTH, 2005, p.31-43), enfatiza a mesma questão, tentando mais uma vez retratar Bin Laden como uma pessoa equilibrada e de considerável perspicácia política. (LAWRENCE; HOWARTH, 2005, p.32):

\begin{abstract}
${ }^{22}$ Ao longo do volume, o 'convite ao Islã' é denotado pelo termo árabe dawa. Dawa tem significado particular no contexto das últimas declarações de Bin Laden aos Estados Unidos e a seus aliados depois do 11 de setembro, nas quais ele lhes oferece uma chance de conversão antes de novos ataques, "deixando claro na concepção islâmica: ele avisou e os convidou antes do ataque". (SCHEUER, Michael. Imperial Hubris: Why the West is Losing the War on Terror.
\end{abstract} [Potomac, 2005], p. 153, tradução nossa).

Além de retratar Bin Laden como uma pessoa equilibrada (ao invés de louco), as introduções e notas de rodapé apresentam impressões dele como "humano", inteligente e perspicaz. O tradutor 
em questão ressalta jogos de palavras inteligentes no discurso de Bin Laden que enfraquecem seu retrato comum como "nosso inimigo' - não lançamos mão normalmente de habilidade verbal ou senso de humor com nossos inimigos. Aqui estão dois exemplos. O primeiro (LAWRENCE; HOWARTH, 2005, p.194) origina-se daquilo que o editor, em uma curta introdução, descreve como a "primeira e única declaração de bin Laden enquadrada como sermão". Faz parte de um áudio de 53 minutos divulgado em vários sites e no jornal al-Hayat.

\section{Texto principal}

Eles procuraram estar com Deus e se privaram do sono enquanto a injustiça estava sendo feita. Eles derramaram água da vida, não água da vergonha. ${ }^{24}$

\section{Nota de rodapé}

${ }^{24}$ Esse é um jogo de palavras em árabe; 'ma' al-hayat ('água da vida') e 'ma' al-mahya' (água da vergonha) são duas palavras formadas a partir da mesma raiz.

O segundo exemplo está no final de uma declaração em áudio divulgada na al-Jazeera no dia 4 de janeiro de 2004 ('Resist the New Rome'; LAWRENCE; HOWARTH, 2005, p. 236):

\section{Texto principal}

Se o chamado de Bush à paz tivesse sido honesto, por que ele não falou da pessoa que cortou a barriga de uma mulher grávida em Sabra e Shatila ou do formulador do processo de rendição ${ }^{3}$, o 'homem da paz' [Ariel Sharon]; por que ele não disse 'odiamos a liberdade e matamos pelo simples prazer'?

\section{Nota de rodapé}

${ }^{3}$ Bin Laden está fazendo um trocadilho aqui: 'processo de paz' é 'amaliyat al-salam', mas ele fala de 'amaliyat al- 
istislam,' o processo de rendição. A palavra para rendição é cognata da palavra para paz.

Notas de rodapé, tais como as mencionadas acima, juntamente com descrições e argumentos indicados tanto na introdução geral do volume e as curtas introduções às traduções individuais são usados cumulativamente para retratar Bin Laden como equilibrado e competente, embora o editor esclareça que isso não significa que ele aprova os métodos de Bin Laden de expressar os seus ressentimentos. O seu argumento, que tem apoio indireto do tradutor em razão de suas escolhas, defende que uma narrativa muito diferente, com um padrão distinto de narratividade causal, pode contribuir para os males atuais do mundo. Ao invés de explicar que a chamada Guerra ao Terror é uma resposta necessária aos horrores cometidos a um Ocidente inocente por extremistas insanos do mundo islâmico, essa nova narrativa de Bin Laden sugere que o Ocidente não é inocente e que a chamada Guerra ao Terror e atrocidades semelhantes são responsáveis pelo extremismo horrível, mas 'racional' vivido hoje. Essa narrativa resiste ao esforço de privar a violência de toda historicidade retratando figuras como Bin Laden simplesmente como extremistas insanos.

\section{Enquadre na tradução: um exemplo expandido}

Um documentário árabe intitulado Jenin Jenin foi dirigido por Mohamed Bakri e divulgado em 2002 após o ataque de Israel ao campo Jenin na Cisjordânia ocupada. O documentário foi filmado no campo Jenin em árabe, mas se destina claramente ao público internacional: foi legendado em inglês, hebraico, francês, espanhol e italiano (Mohamed Bakri, comunicação pessoal). A versão com legendas em inglês parece destinar-se predominantemente ao público americano, como veremos a seguir. Os exemplos seguintes do documentário demonstram duas tentativas de (re)enquadre que respondem a narrativas maiores que acompanham o texto imediato 
e não podem ser explicadas com o uso da teoria das normas ou da dicotomia estrangeirização versus domesticação de Venuti. Ambos os exemplos são discutidos a partir de diferentes perspectivas em Baker (2006, p. 99-100, 64-66).

\section{O enquadre do Vietnã}

O primeiro exemplo de (re)enquadre ativa uma estrutura narrativa que parece funcionar melhor no contexto de destino. Em uma parte do documentário, um homem velho palestino expressa seu choque em relação ao que aconteceu em Jenin e à aparente indiferença e relutância do mundo de interferir para proteger os palestinos. A sua participação termina quando ele diz literalmente em árabe, "O que posso dizer, por Deus, por Deus, nossa casa/nosso lar não é mais uma casa/um la". A legenda desse enquadre é "O que eu posso dizer? Nem mesmo no Vietnã foi tão ruim assim” (ver Figura 4).

A decisão de substituir a referência original ligada à destruição de casas palestinas pela referência ao Vietnã é tradicionalmente interpretada nos estudos de tradução como uma tentativa de 'aculturar' o texto original, para torná-lo mais inteligível ao público de destino (neste caso o público predominantemente americano). Mas essa não é uma explicação muito produtiva ou mesmo satisfatória. Tivesse essa sido a motivação principal, faria mais sentido referir-se a um evento mais recente e importante, tal como o 11 de setembro. Afinal, pode-se argumentar que o Vietnã exerce menor repercussão no público americano jovem do que o 11 de setembro, e recorrer à memória desse público implica possivelmente maior envolvimento emocional e simpatia de uma ampla parcela do público americano. Para compreender a motivação dessa escolha de tradução assim como suas implicações, é necessário referir-se a narrativas mais amplas em circulação naquela época, na Palestina e no mundo. 


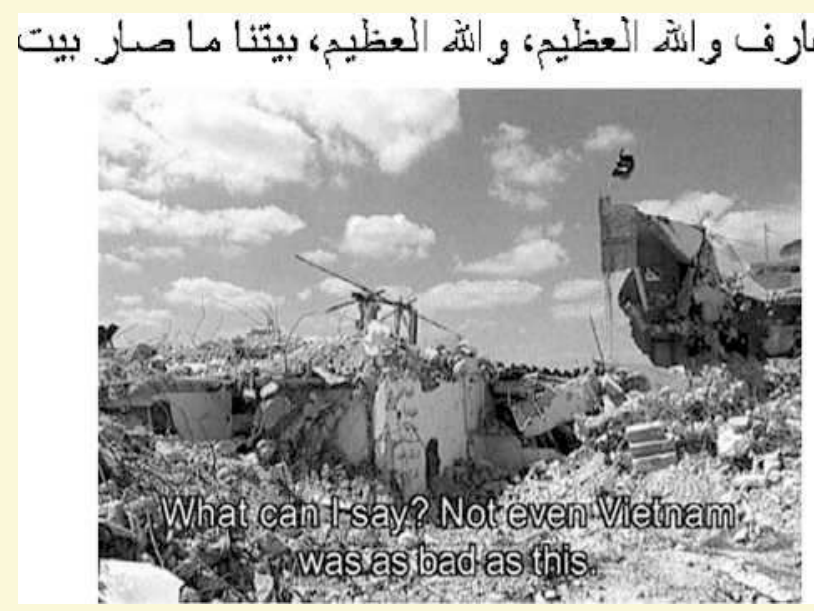

Figura 4 Foto de Jenin Jenin

Primeiramente, foi e continua a ser fortemente contestada a narrativa imediata do que realmente aconteceu no campo Jenin e em outros lugares na Palestina ocupada em abril de 2002 q questionamentos desde a razão de as Forças [sic] de Defesa de Israel terem invadido os campos ao fato de eles terem destruído muitas casas e matado pessoas, e assim por diante. Um dos tópicos discursivos de contestação à época referia-se à descrição ampla do evento em Jenin, na mídia destinada a falantes do inglês, como 'incursão'. Ativistas do movimento Solidariedade insistem que 'incursão' é um termo muito ameno para a descrição do ataque coordenado e incisivo que deixou o campo em ruínas e muitas pessoas mortas. A referência ao Vietnã na legenda acima permite um reenquadre do evento como uma guerra de agressão, ao invés de um ataque menor como o termo 'incursão' tende a sugerir. $\mathrm{O}$ Vietnã não representou certamente uma incursão: é considerada uma guerra violenta e sangrenta por grandes segmentos do público americano e internacional.

Em segundo lugar, uma narrativa que continua a ter força considerável entre palestinos assim como entre um crescente movimento 
internacional de solidariedade em apoio aos direitos dos palestinos, defende que os Estados Unidos são tão responsáveis quanto Israel pelas atrocidades cometidas - Israel não poderia ter conduzido essa opressão aos palestinos se não tivesse tido o apoio amplo dos Estados Unidos. A escolha do Vietnã aqui ativa essa narrativa pública. A despeito de estrangeirizante ou domesticadora, a escolha de usar a narrativa do Vietnã codifica tanto acomodação à dominação como resistência a ela. Essa escolha se ajusta à dominação em razão de uma referência (Vietnã) que tem ressonância no público dominante americano, ao invés de uma que poderia igualmente sinalizar atos injustos e sangrentos de agressão, mas que não teria ressonância nesse público dominante: Caxemira, nesse caso, ou até mesmo Darfur. Essa codifica resistência ao enquadrar os Estados Unidos como agressor e simultaneamente sinalizar que o público americano é cúmplice das injustiças perpetradas pelo governo - e pode escolher questioná-las, tal como fizeram no caso do Vietnã.

\section{O enquadre secular}

Uma outra tentativa interessante de enquadre da ampla narrativa palestina por meio do reposicionamento de aspectos do discurso de vários palestinos entrevistados nesse documentário refere-se ao tratamento da palavra recorrente shaheed. O equivalente dessa palavra em inglês é martyr, mas isso é problemático por duas razões. Primeiramente, o significado de shaheed não corresponde exatamente em termos semânticos a martyr em inglês. Em árabe, shaheed é geralmente usado para se referir a alguém que é morto violentamente, em especial na guerra, mesmo se a pessoa tiver ou não escolhida para combater na guerra, sem fazer referência a sua religião. Essa palavra não faz referência à militância e ao extremismo que martyr adquiriu em inglês, com relação ao mundo árabe e islâmico. ${ }^{12}$ Em segundo lugar, martyr evoca associações

12 Martyr naturalmente apresenta diferentes associações em outros contextos, como por exemplo no discurso do Cristianismo. 
imediatas com o fundamentalismo islâmico nesse tipo de contexto, e o uso dela repetidamente serve àqueles que retratam o conflito no Oriente Médio como uma guerra religiosa, acirrada por muçulmanos insanos em busca de virgens no paraíso. As legendas, de forma coerente, trazem a opção por equivalentes diferentes quando a palavra shaheed é usada por palestinos entrevistados no documentário, como nos seguintes exemplos (ver BAKER 2006a, p. 64-66):

Exemplo 1

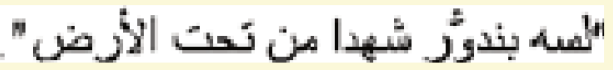

Retrotradução

We are still pulling martyrs from underneath the ground

Legenda em inglês

We are still pulling victims out of the rubble

\section{Exemplo 2}

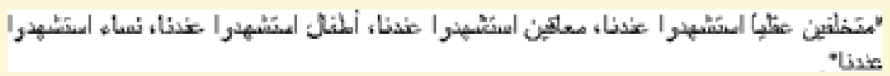

\section{Retrotradução}

We have mentally retarded people who have been martyred; we have disabled people who have been martyred; we have children who have been martyred, we have women who have been martyred.

\section{Legenda em inglês}

They killed some mentally disabled people, children and women in the camp.

A escolha de equivalentes tais como victims 'vítimas' e killed 'mataram' nos exemplos acima (e corpses 'corpos' e dead 'mortos' em outras partes, discutidos em Baker 2006a) ao invés de martyr auxilia o enquadre da narrativa palestina e árabe em termos mais seculares. 
Há duas exceções em todo o documentário. A primeira ocorre no final de uma cena que retrata uma criança palestina de sete ou oito anos demonstrando coragem e determinação de sobrevivência ao longo do documentário. A criança permite estabelecer analogia mais ampla entre o campo Jenin e uma 'árvore alta, robusta em forma de torre, que se constitui de folhas', tendo cada uma a 'inscrição do nome shaheed, um muqawim [lutador de resistência]' (tradução minha). As legendas mantêm a metáfora e a referência aos 'martyrs' nessa parte, apesar de, pode-se argumentar, a aparência inocente, talvez desafiadora, da criança não se enquadrar exatamente na imagem de um extremista insano em busca do paraíso:

The camp is like a tall, eminent tree. The tree has leaves, and each leaf of the tree bears the name of a martyr. ${ }^{13}$

O segundo uso da palavra martyr ocorre nos créditos finais, não sendo, portanto, uma "legenda". O documentário inicia-se com a seguinte dedicatória (reproduzida a seguir sem correção):

\author{
Dedicated to \\ The Executive Producer of 'Jenin' \\ IYAD SAMOUDI \\ who was murdered at alyamoun \\ at the end of the filming by \\ Israelian soliders on $23 / 06 / 2003$ \\ Mohamed Bakri
}

Os créditos finais incluem o texto seguinte: ${ }^{13}$ Observe que as legendas, no entanto, enfraquecem as imagens ao omitir "lutador
de resistência". 
Executive Producer

The martyr

lyad Samoudi

Essas escolhas aparentemente conflitantes no tratamento de shaheed/shohadaa refletem a interação entre dominação e resistência, que é parte essencial da vida cotidiana. Essas não podem, e não deveriam, ser consideradas escolhas aleatórias e sem motivação por parte dos tradutores e profissionais em geral, nem deveriam ser varridas para debaixo do tapete pelo fato de não se enquadrarem em padrões existentes e dicotomias conceituais.

\section{Considerações finais}

Para resumir, a teoria narrativa nos permite compreender essas estratégias aparentemente conflitantes, tais como aquelas relacionadas à escolha de equivalentes para shaheed em partes diferentes do documentário Jenin Jenin, assim como aquelas (como a escolha de Vietnã acima) que são simultaneamente estrangeirizantes e domesticadoras. Em oposição a conceitos estáticos, insensíveis a questões de poder, como o conceito de 'norma', a teoria narrativa reconhece que a dominação e a resistência não apenas modelam nosso comportamento e escolhas discursivas, mas estão também sempre em uma relação de tensão. Essa tensão ocorre geralmente no âmbito discursivo, e a interação entre os dois conceitos pode produzir uma variedade de escolhas difíceis de delimitação. Em vez de ignorar escolhas que não se adéquam a um padrão recorrente, o reconhecimento da interação entre dominação e resistência nos permite elaborar uma concepção mais complexa da posição dos tradutores e inseri-los em uma realidade política concreta. 


\section{Referências}

ASIMAKOULAS, D. Brecht in dark times: Translations of his works under the Greek Junta (1967-1974). Target 17(1), [S.L], p. 93-110, 2005.

BAKER, M. Narratives in and of translation. SKASE Journal of Translation and Interpretation 1(1), [S.L], p. 4-13, 2005. Disponível em: <www.skase.sk>.

. Translation and conflict: A narrative account. London: Routledge, $2006 a$.

. Translation and activism: Emerging patterns of narrative community. The Massachusetts Review XLVII (3), [S.L], p. 462-84, $2006 \mathrm{~b}$.

CUNNINGHAM, D.; BROWNING, B. 2004. The emergence of worthy targets: Official frames and deviance narratives within the FBI. Sociological Forum 19(3), [S.L], p. 347-69, 2004.

FISHER, W. R. (1987). Human communication as Narration: Toward a philosophy of reason, value, and action. Columbia, South Carolina: University of South Carolina Press, 1989.

GLASS, C. Cyber-Jihad. London Review of Books 28(5), [S.L], p. 14-18, 2006.

GODDARD, B. Theorizing feminist discourse/translation. In: BASSNET, Susan; LEFEVERE, André (Org.). Translation, history and culture. London: Pinter Publishers, 1990. p. 87-96.

GOFFMAN, E. (1974). Frame analysis: An essay on the organization of experience. Boston, Mass.: Northeastern University Press, 1986.

HALL, J. R.; NEITZ, M. J.; BATTANI, M. Sociology on culture. London: Routledge, 2003. 
HARVEY, K. Translating camp talk. Gay identities and cultural transfer. The Translator 4(2), [S.L], p. 295-320, 1998.

. Intercultural movements. American gay in French translation. Manchester: St Jerome Publishing, 2003a.

. "Events" and "horizons": Reading ideology in the "bindings" of translations. In: PÉREZ, María Calzada (Org.). Apropos of ideology -/Translation studies on ideology - Ideologies in translation studies. Manchester: St Jerome Publishing, 2003b. p. 43-69.

HUNTINGTON, S. The clash of civilizations. Foreign Affairs 72(3), [S.L], p. 22-49, 1993.

. The clash of civilizations and the remaking of world order. New York: Touchstone, 1996.

. Sidam Al Hadarat wa I'adat Son' Al-Nizam Al 'Alami [The clash of civilizations and the remaking of world order]. Tradução de Tal'at Al-Shayib. Cairo: Sutur, 1998.

. Sidam Al Hadarat wa I'adat Bina' Al-Nizam Al 'Alami [The clash of civilizations and the rebuilding of world order]. Tradução de Malik Obeid Abu Shuhaya; Mahmoud Mohammed Khalaf. Benghazi: Al-Dar Al-Jamahiriyya lilnashr wa-ltawzee' wa-li'laan, 1999.

KATAN, D. (1999). Translating cultures. 2. ed. Manchester: St Jerome Publishing, 2004.

KEENAGHAN, E. Jack Spicer's pricks and cocksuckers. Translating gay desire into visibility. The Translator 4(2), [S.L], p. 273-94, 1998.

LAWRENCE, B. (Org.). Messages to the world: The statements of Osama Bin Laden. Tradução de J. Howarth. London: Verso, 2005.

SIMON, Sherry. Gender in translation. London \& New York: Routledge, 1996. 
SOMERS, M. Narrativity, narrative identity, and social action: Rethinking English working-class formation. Social Science History 16(4), [S.L], p. 591630, 1992.

. The narrative construction of identity: A relational and network approach. Theory and Society 23(5), [S.L], p. 605-49, 1994.

. Deconstructing and reconstructing class formation theory: Narrativity, relational analysis, and social theory. In: HALL, J. R. (Org.). Reworking class. Ithaca, N.Y.: Cornell University Press, 1997. p.73-105

SOMERS, M. R.; GIBSON, G. D. Reclaiming the epistemological "Other': Narrative and the social constitution of identity. In: CALHOUN, Craig (Org.). Social theory and the politics of identity. Oxford, UK: Blackwell, 1994. p.37-99.

TANNEN, D.; WALLAT, C. Interactive frames and knowledge schemas in interaction: Examples from a medical examination/interview. In: TANNEN: Deborah (Org.). Framing in discourse. New York: Oxford University Press, 1993. p.57-76.

TOURY, G. In search of a theory of translation. Tel Aviv: Porter Institute, 1980.

. Descriptive translation studies and beyond. Amsterdam: John Benjamins, 1995.

VENUTI, L. Translation as cultural politics: Regimes of domestication in English. Textual Practice 7, [S.L], p. 208-23, 1993.

. The translator's invisibility. London: Routledge, 1995.

. Introduction. Translation and minority. The Translator 4(2), [S.L], p. 135-44, 1998. Edição especial.

von FLOTOW, L. Translation and gender. Translating in the "era offeminism". Manchester: St Jerome Publishing, 1997. 
WATTS, R. Translating culture: Reading the paratexts of Aimé Césaire's Cahier d'un retour au pays natal. TTR XIII (2), [S.L], p. 29-46, 2000.

WHITEBROOK, M. 2001. Identity, narrative and politics. London: Routledge, 2001.

Recebido em: 22/04/2018

Aceito em: 10/06/2018

Publicado em setembro de 2018

Cristiane Roscoe-Bessa. E-mail: crbessa@unb.br ORCID: https://orcid.org/0000-0002-8293-7926

Flávia Lamberti. E-mail: flavialamberti@gmail.com

ORCID: https://orcid.org/0000-0002-8216-2892 